\title{
Modified method for fracability evaluation of tight sandstones based on interval transit time
}

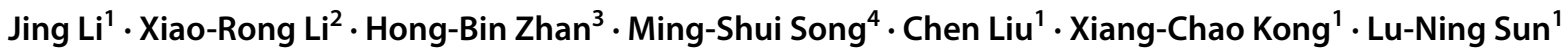

Received: 20 January 2019 / Published online: 29 November 2019

(C) The Author(s) 2019

\begin{abstract}
Fracability is a property that indicates how easy reservoir rocks can be fractured in hydraulic fracturing operations. It is a key parameter for fracturing design and evaluation. In order to utilize continuous logging data to predict fracability, synchronous tests of dynamic and static mechanical parameters of rocks under different confining pressures were conducted on 13 tight sandstone samples derived from the central Junggar Basin, China. A modified formula between dynamic and static mechanical parameters was established. Fracability of the tight reservoir in the Junggar Basin was then evaluated based on brittleness index, fracture toughness, and fracability index. The effectiveness of fracturing was analyzed combined with the oil testing curve after hydraulic fracturing. The results show that: (1) The distribution of oil-bearing formations in the studied area coincides well with stratum of higher fracability index. (2) The critical fracability index is determined to be 0.3 , three formations are selected as fracturing candidates, and a thin mudstone interbed is identified in the oil-bearing formation. (3) Well testing curve verifies the reliability of the fracability evaluation method and the accuracy of the modified formula between dynamic and static mechanical parameters. This study provides useful information for improving fracturing operations of tight oil and gas reservoirs.
\end{abstract}

Keywords Tight sandstone $\cdot$ Brittleness index $\cdot$ Fracture toughness $\cdot$ Fracability index

\section{Introduction}

With the increasing development of unconventional oil and gas, tight oil and gas has become a promising resource of oil and gas exploitation. Because of low porosity and permeability of tight reservoirs, hydraulic fracturing is usually

Edited by Yan-Hua Sun

$\triangle$ Jing Li

lijing0681@163.com

Xiao-Rong Li

xiaorongli@cup.edu.cn

1 College of Pipeline and Civil Engineering, China University of Petroleum (East China), Qingdao 266580, Shandong, China

2 College of Safety and Ocean Engineering, China University of Petroleum (Beijing), Beijing 102249, China

3 Department of Geology and Geophysics, Texas A\&M University, College Station, TX 77843, USA

4 Sinopec Shengli Oilfield Company, Dongying 257001, Shandong, China needed to ensure productivity. Fracability is the property that indicates how easy a reservoir rock can be fractured. It serves as a key parameter for the design and evaluation of hydraulic fracturing jobs (Govindarajan et al. 2017).

Extensive studies have been carried out on the fracability of shale gas and tight gas reservoirs. For instance, Tarasov and Potvin. (2013) calculated the brittleness of rocks from hardness and firmness and showed that only two of many existing criteria can properly describe the intrinsic material brittleness. Li et al. (2015) calculated the rock brittleness index using the composition and content of rock minerals. Mullen calculated elastic modulus and Poisson's ratio using acoustic logging data (Rickman et al. 2008). These methods for evaluating the brittleness of rock are to judge the degree of difficulty of fracture initiation. However, the formation of a complex fracture network system requires that not only the rocks are more prone to fracture initiation but also the generated fractures have a good ability to extend. In other words, fracability is also related to fracture toughness of rock (Yuan et al. 2017). Several investigators measured fracture toughness of sandstones and shales and studied the relationship between the fracture toughness and the tensile strength 
(Sierra et al. 2010; Chen et al. 2015). Neither brittleness index nor fracture toughness alone could fully evaluate the fracturing ability of rocks. Other researchers suggested that the fracture initiation and extension should be considered in an integrated manner in the evaluation of rock fracability. Some evaluation methods involving two kinds of parameters have been proposed (Jin et al. 2014; Sun et al. 2015).

In summary, rock fracability is mostly determined using laboratory tests to measure the static mechanical parameters of rock. However, the cost of measuring these parameters is usually very high and sometimes prohibitive. In contrast, the dynamic mechanical parameters of rock can be easily obtained using standard logging data and the cost of measurement is much lower. Therefore, determining the relationship between dynamic and static mechanical parameters is a key to evaluate rock fracability using logging data, which is the primary goal of this study.

Rock samples from a deep tight oil reservoir in the Junggar Basin were used to conduct synchronous dynamic and static mechanical experiments. Based on the results, a correction formula between dynamic and static mechanical parameters was established. Using the new formula, formation brittleness index, fracture toughness, and fracability index could be calculated. According to selected critical fracturing index, optimum sections for conducting hydraulic fracturing could be determined. Finally, a plan for hydraulic fracturing was put forward based on the analysis.

\section{Synchronous measurement of dynamic and static mechanical parameters of rocks}

Rock mechanical parameters can be obtained through static and dynamic testing methods. In general, static and dynamic mechanical parameters of rocks are different and the static parameters should be used in practical engineering design (Li et al. 2011). Mechanical parameters calculated from logging data reflect the mechanical properties of the rock under instantaneous loading, i.e., the so-called dynamic mechanical properties. In reality, rocks are under long-term, largestrain static stress state, i.e., the so-called static state.

Due to the complex nature of sedimentary environments, diagenesis, structure, and tectonic movement in different regional stratum, it is very difficult or even impossible to establish a universal formula correlating static with dynamic parameters of rocks. Therefore, in many occasions, one has to carry out static and dynamic tests independently for a given sample to establish such a formula. In this study, synchronous experiments for measuring dynamic and static mechanical parameters of 13 groups of rock samples taken from the central Junggar Basin in China were carried out. A formula that is capable of correlating static with dynamic rock parameters based on the experimental results was established.

\subsection{Experimental apparatus and rock samples}

An RTR-1500 servo-controlled testing machine (GCTS Company, USA) was used for the experimental study. The maximum axial load, maximum confining pressure, and maximum temperature of the systems were $1500 \mathrm{kN}$, $140 \mathrm{MPa}$, and $150{ }^{\circ} \mathrm{C}$, respectively. The experimental precision was controlled as follows: $0.01 \mathrm{MPa}$ of pressure, $0.01 \mathrm{~mL}$ of liquid volume, and $0.001 \mathrm{~mm}$ of deformation. The mechanical parameters and sonic wave velocity (compressional and shear wave) of the rock were measured simultaneously at high temperature and high pressure. The core samples were sandstone cylinders with a diameter of $25 \mathrm{~mm}$ and a height of about $50 \mathrm{~mm}$. Specifications of those cores are presented in Table 1.

\subsection{Experimental procedures}

The specific experimental procedures are as follows:

Step 1 Sonic wave tests were carried out. The wave velocity and wave slowness of the compressional wave $(\mathrm{P})$ and shear wave ( $\mathrm{S}$ ) were calculated by measuring the ultrasonic arrival time.

Step 2 The triaxial compression tests were conducted on rock samples. Different confining pressures of 0,10 , 20,30 , and $40 \mathrm{MPa}$ were applied, respectively, and the axial load was increased until the failure of rock samples occurred. The loading rate of strain was $2 \times 10^{-5} \mathrm{~s}^{-1}$.

Step 3: The axial stress, axial displacement, and the lateral displacement in the experiment were recorded, and the stress-strain curve of the samples was plotted.

\subsection{Experimental results}

The dynamic elastic modulus and dynamic Poisson's ratio can be calculated using the acoustic wave velocity measured in the experiments. For an isotropic linear elastic rock medium, there is a certain correlation between Poisson's ratio, elastic modulus, and velocities of compressional and shear waves based on the elastic wave propagation theory (Winkler et al. 1979), as expressed in Eqs. (1) and (2), respectively.

$E_{\mathrm{d}}=\frac{\rho\left(3 \Delta t_{\mathrm{s}}^{2}-4 \Delta t_{\mathrm{p}}^{2}\right)}{\Delta t_{\mathrm{s}}^{2}\left(\Delta t_{\mathrm{s}}^{2}-\Delta t_{\mathrm{p}}^{2}\right)} \times 9.299 \times 10^{4}$ 


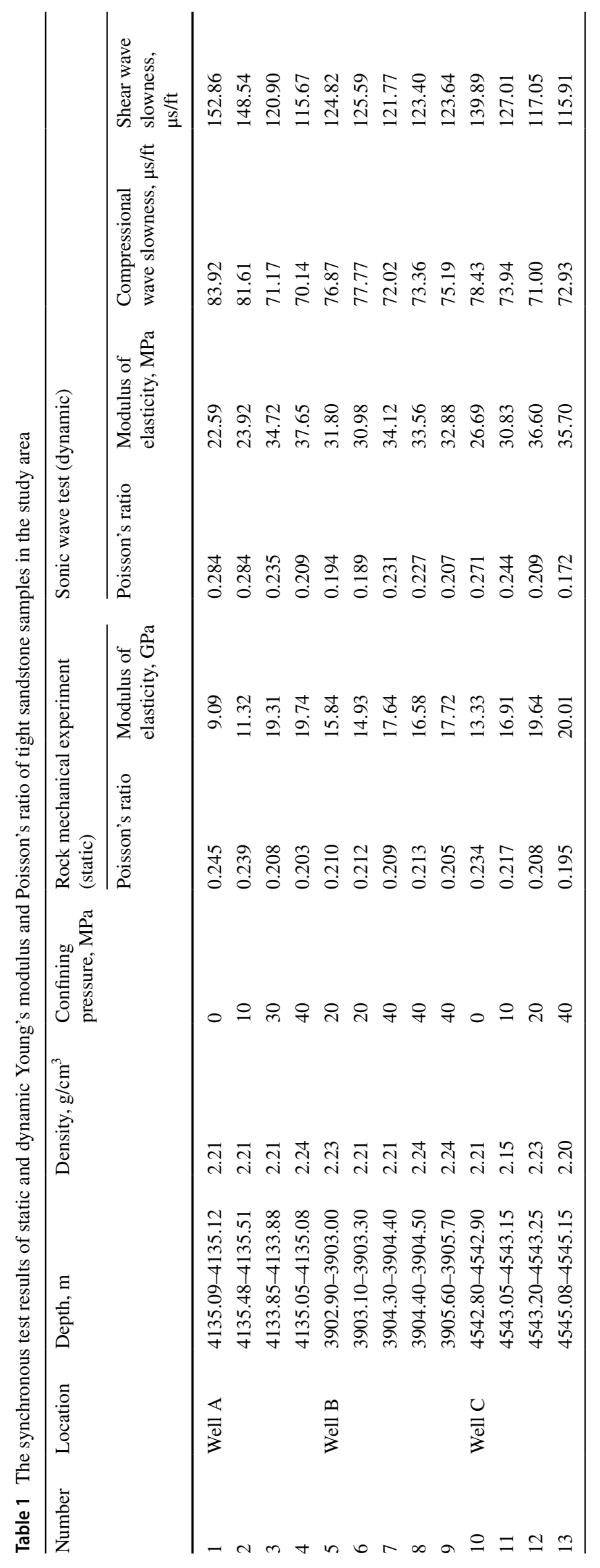


$\mu_{\mathrm{d}}=\frac{0.5 \Delta t_{\mathrm{s}}^{2}-\Delta t_{\mathrm{p}}^{2}}{\Delta t_{\mathrm{s}}^{2}-\Delta t_{\mathrm{p}}^{2}}$

where $E_{\mathrm{d}}$ is the dynamic elastic modulus, $\mathrm{GPa} ; \mu_{\mathrm{d}}$ is the dynamic Poisson's ratio, dimensionless; $\Delta t_{\mathrm{s}}$ and $\Delta t_{\mathrm{p}}$ are the shear and compressional wave slowness of the rock, respectively, $\mu \mathrm{s} / \mathrm{ft}$, where the wave slowness is the reciprocal of the wave velocity; $\rho$ is the rock density, $\mathrm{g} / \mathrm{cm}^{3}$; and the constant $9.299 \times 10^{4}$ in Eq. (1) is a coefficient induced by unit transformation of $\Delta t$ from $\mu \mathrm{s} / \mathrm{m}$ to $\mu \mathrm{s} / \mathrm{ft}$.

In the triaxial compression tests, shear failure occurred in all 13 groups of tight sandstone samples. Comparisons between pre-test and post-test cores are shown in Fig. 1.

The complete stress-strain curves measured in the experiment are shown in Fig. 2. It can be seen that the samples

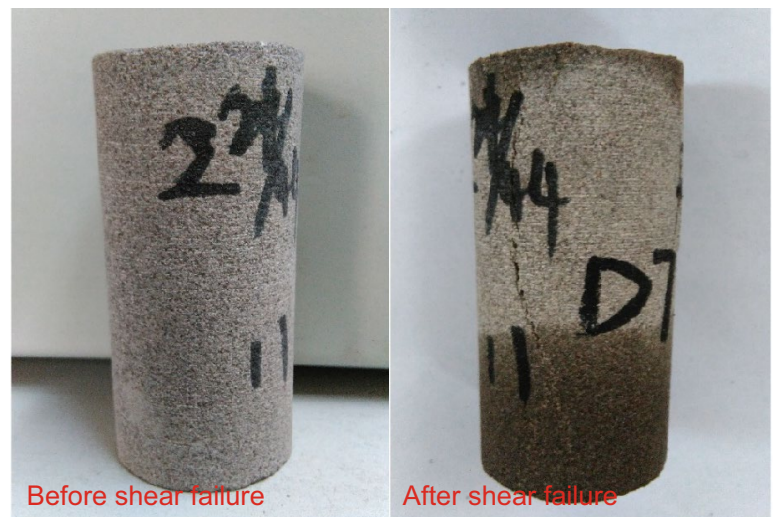

No. 2 core experienced three stages of deformation: a compaction stage, an elastic stage, and a plastic stage before failure. The samples were damaged after the peak stress was reached. The static modulus and Poisson's ratio of each sample were calculated using the stress-strain relationship of the elastic stage in the diagram. The results are reported in Table 1.

\subsection{Relationships between static and dynamic mechanical parameters of rocks}

According to the results of above synchronous experiments for rock samples from the central Junggar Basin, a cross-plot between the static and dynamic modulus and Poisson's ratio was drawn. Linear relationships were observed between the static and dynamic parameters as shown in Fig. 3 and are expressed by Eqs. (3) and (4).
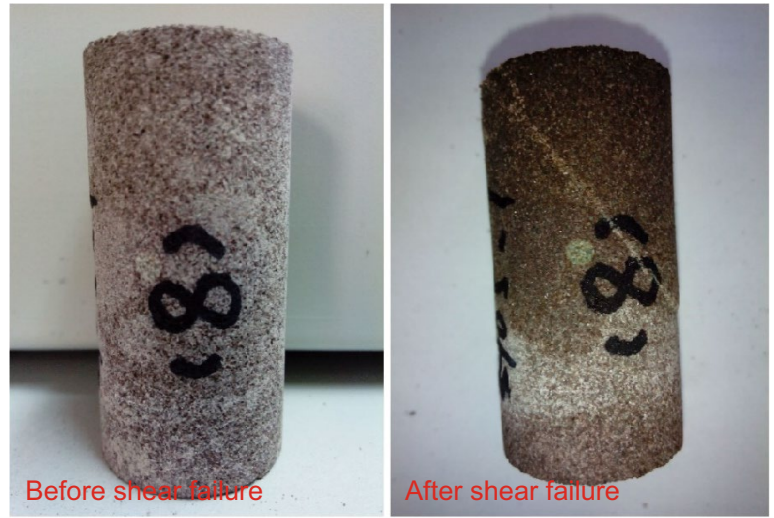

No. 8 core

Fig. 1 Core samples before and after shear failure

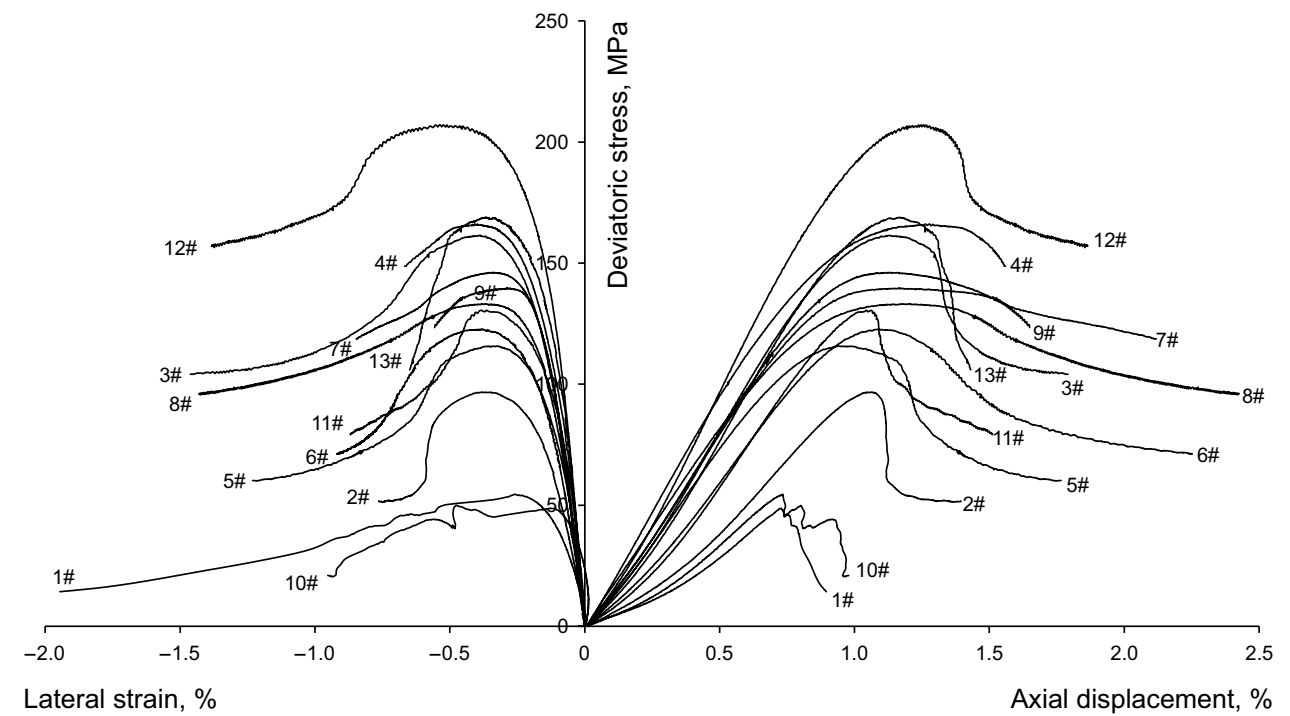

Fig. 2 Complete stress-strain curves of different confining pressure tests of tight sandstones 


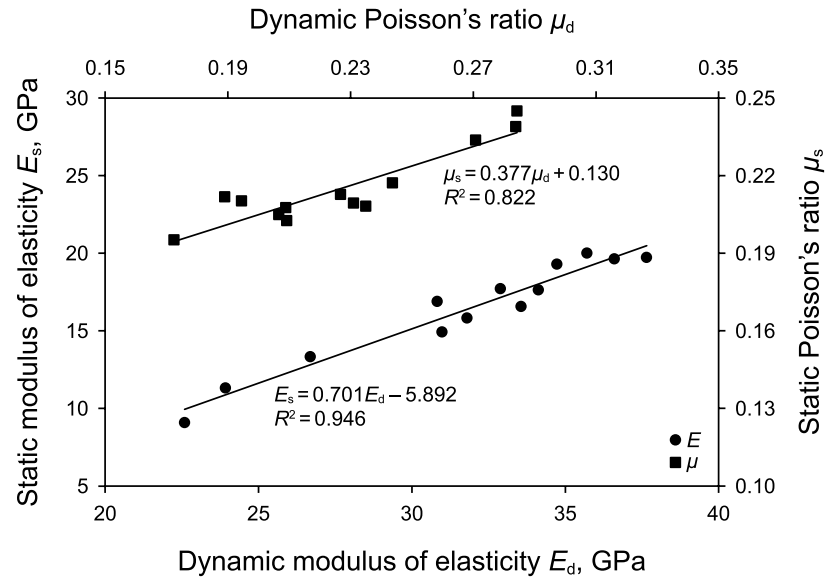

Fig. 3 The cross-plot of dynamic and static Young's modulus and Poisson's ratio

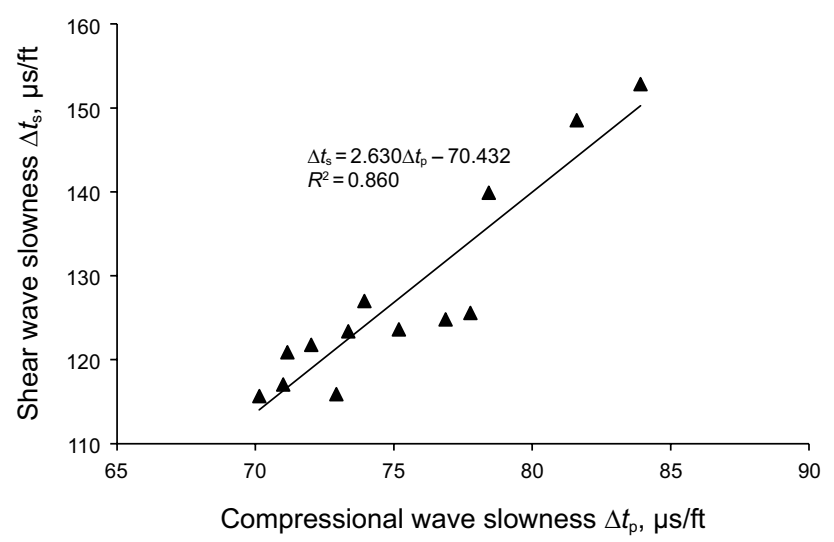

Fig. 4 The cross-plot of the compressional and shear wave slowness in acoustic wave tests

$E_{\mathrm{s}}=0.701 E_{\mathrm{d}}-5.892$

$\mu_{\mathrm{s}}=0.377 \mu_{\mathrm{d}}+0.130$

where $E_{\mathrm{s}}$ is the static modulus of elasticity, $\mathrm{GPa}$, and $\mu_{\mathrm{s}}$ is static Poisson's ratio. These relationships are applicable to the central Junggar Basin.

The dynamic modulus and Poisson's ratio of rock samples can be calculated using compressional and shear wave slowness data in the logging, which can only be obtained simultaneously using complete acoustic waveform logging or dipole shear wave logging. Unfortunately, in practice, this is seldom done, as the compressional wave logging is usually the only dataset available. This is particularly true in the Junggar Basin in China. In this case, it is necessary to calculate the shear wave slowness using the compressional wave slowness. To fulfill this demand, a cross-plot of the compressional and shear wave slowness was created as shown in Fig. 4, and a linear regression relation between them was established as:

$\Delta t_{\mathrm{s}}=2.630 \Delta t_{\mathrm{p}}-70.432$

\section{Fracability evaluation}

The fracability of reservoir rocks mainly reflects two aspects: the degree of difficulty for fracture initiation and the degree of difficulty for propagation. The former can be reflected by the brittleness index, and the latter is usually represented by the fracture toughness. Only when the reservoir rocks have both high brittleness index and low fracture toughness, can complex fracture networks be formed in the process of hydraulic fracturing.

\subsection{Brittleness index}

The rock brittleness represents the speed of the failure process when the rock is subjected to the ultimate load. Highbrittleness rocks have very small plastic deformation before failure. On the contrary, the plastic deformation before failure of rocks with low brittleness is relatively large. The rock brittleness can be represented by the brittleness index. A higher brittleness index means that the rock is more brittle and is easier to form a complex fracture network in fracturing jobs. Therefore, the brittleness index is one of the key parameters for evaluating the reservoir fracability.

The brittleness index has many different expression forms and can be measured using various methods (Li et al. 2012). The most widely used method is the Rickman method (Rickman et al. 2008):

$B=\frac{E_{\mathrm{n}}+\mu_{\mathrm{n}}}{2}$

$E_{\mathrm{n}}=\frac{E-E_{\min }}{E_{\max }-E_{\min }}$

$\mu_{\mathrm{n}}=\frac{\mu-\mu_{\min }}{\mu_{\max }-\mu_{\min }}$

where $B$ is the brittle index of the rock, dimensionless; $E_{\mathrm{n}}$ is the normalized modulus, dimensionless; $\mu_{\mathrm{n}}$ is the normalized Poisson's ratio, dimensionless; $E$ is the static modulus, $\mathrm{GPa} ; E_{\max }$ and $E_{\min }$ are the maximum and minimum static modulus of the investigated rock layer, respectively, GPa; $\mu$ is the static Poisson's ratio, dimensionless; $\mu_{\max }$ and $\mu_{\min }$ are the maximum and minimum static Poisson's ratio of the investigated rock layer, respectively, dimensionless. The 
static modulus and Poisson's ratio can be calculated by logging data based on Eqs. (1)-(5).

\subsection{Fracture toughness}

High-brittleness formations are easier for fracture initiation. For fractures to become effective conduction channels, the fractures should also have good extension capability. Irwin's fracture mechanics states that the condition for fracture propagation is the stress intensity factor at the fracture tip exceeding the critical value for fracture propagation, which is the so-called fracture toughness (Irwin 1956). The fracture toughness reflects the capability of the rock to resist fracture propagation. The larger the fracture toughness, the harder the fracture to propagation.

There are two common methods to obtain the fracture toughness of rocks. One is to measure the fracture toughness of the rock directly using rock mechanical experiments such as disk experiments and hydraulic fracturing experiments. The direct measurement methods usually have higher accuracy but have some disadvantages such as difficulty in coring, time-consuming, data dispersion, and high cost. The other method is to establish a relationship between the fracture toughness and the tensile strength of the rock (Jin et al. 2001). This indirect method can obtain a continuous fracture toughness profile of the formation using logging data. In addition, it is less expensive and less time-consuming. Therefore, the indirect method has become the most commonly used method to obtain the fracture toughness in the petroleum industry.

Sierra et al. (2010) proposed a relationship between the fracture toughness and the tensile strength of shales based on experimental results:

$K_{\mathrm{IC} 1}=0.271+0.107 \sigma_{\mathrm{t}}$

where $K_{\mathrm{IC} 1}$ is the fracture toughness, MPa $\cdot \mathrm{m}^{1 / 2}$, and $\sigma_{\mathrm{t}}$ is the tensile strength, MPa. The tensile strength can be further related to the dynamic elastic modulus and the shale content of rock samples:

$\sigma_{\mathrm{t}}=\frac{E_{\mathrm{d}}\left(0.0045+0.0035 V_{\mathrm{sh}}\right)}{12.26}$

where $V_{\text {sh }}$ is the shale content.

A similar relationship between the fracture toughness and the tensile strength of sandstones was also obtained based on previous experimental results (Chen et al. 1997), as shown in Fig. 5 and Eq. (11).

$K_{\mathrm{IC} 2}=0.236+0.091 \sigma_{\mathrm{t}}$

Both Eqs. (9) and (11) show that there is a linear relationship between the fracture toughness and the tensile strength.

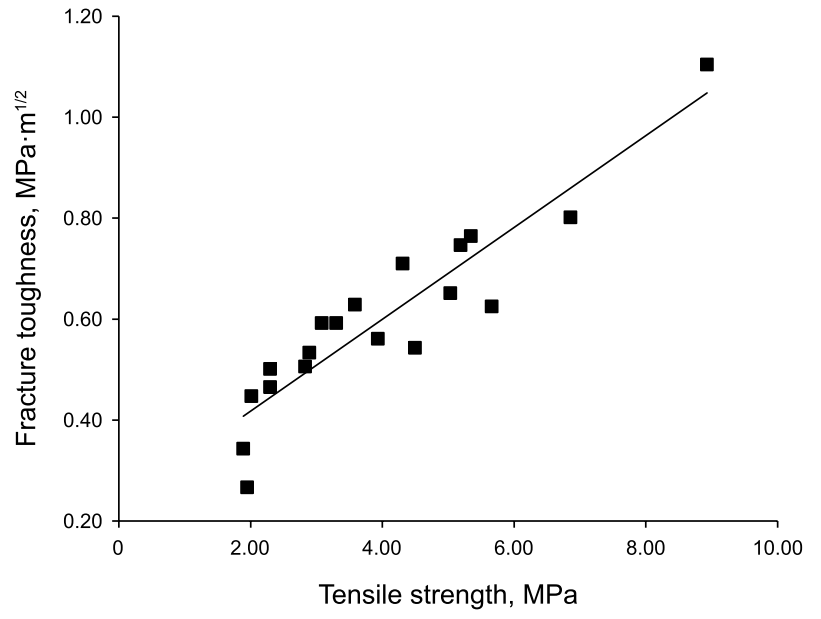

Fig. 5 The relationship between the fracture toughness and the tensile strength (Chen et al. 1997)

Table 2 The empirical formulas of fracability index

\begin{tabular}{lll}
\hline References & Formula & Remarks \\
\hline Jin et al. (2014) & $F=w B_{\mathrm{n}}+(1-w) K_{\mathrm{IC} \_\mathrm{n}}$ & Weighting method \\
Sun et al. (2015) & $F=B_{\mathrm{n}} K_{\mathrm{IC} \_\mathrm{n}}$ & Product method \\
\hline
\end{tabular}

$F$ is the fracability index, dimensionless; $B_{\mathrm{n}}$ is the normalized brittleness index, dimensionless; $K_{\mathrm{IC} n}$ is the normalized fracture toughness, dimensionless

This implies that for tight sandstones it is possible to deduce the fracture toughness from the rock strength.

\subsection{Fracability index}

Fracability is a key index for evaluating the fracture effectiveness of rocks and the formation of a fracture network during hydraulic fracturing. Therefore, fracability should incorporate the information of brittleness index and fracture toughness. Jin et al. (2014) and Sun et al. (2015) combined the brittleness index and the fracture toughness and established computational methods for calculating the rock fracability index, namely the weighting method and the product method, respectively, as shown in Table 2.

The brittleness index and the fracture toughness are both normalized as follows:

$B_{\mathrm{n}}=\frac{B-B_{\min }}{B_{\max }-B_{\min }}$

$K_{\mathrm{IC}_{\mathrm{n}}}=\frac{K_{\mathrm{IC}_{\max }}-K_{\mathrm{IC}}}{K_{\mathrm{IC}_{\max }}-K_{\mathrm{IC}_{\text {min }}}}$ 

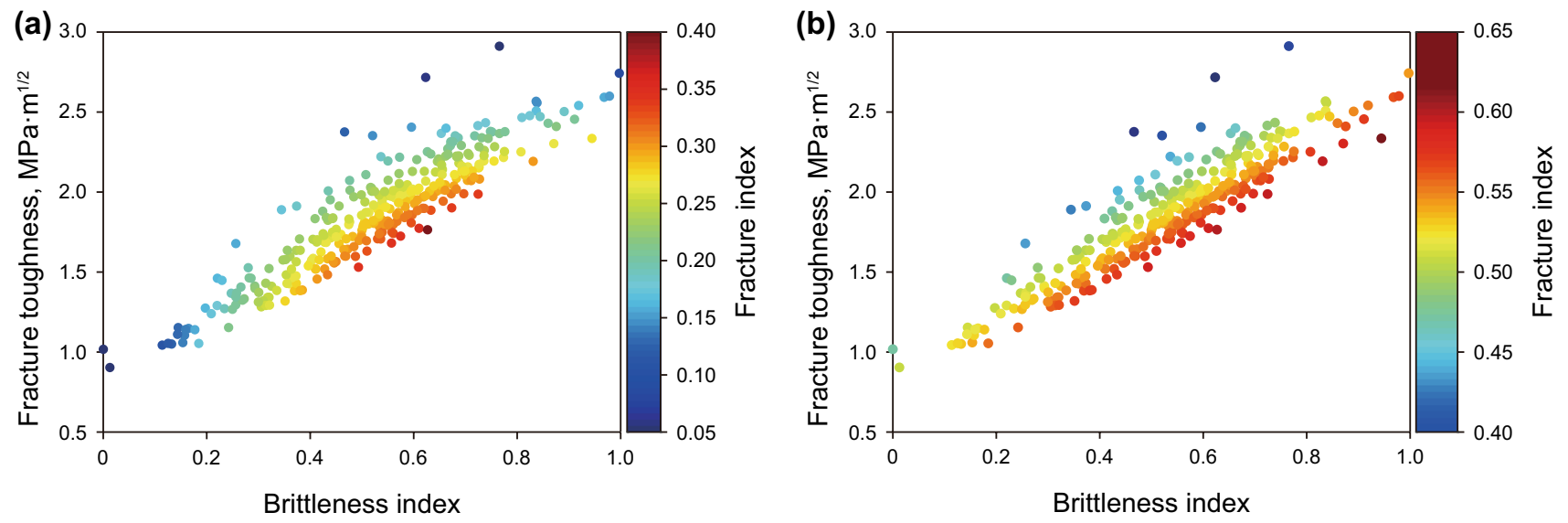

Fig. 6 Comparison of different empirical equations for calculating the fracability index. a Product method. b Weighting method

where $B_{\max }$ and $B_{\min }$ are the maximum and the minimum brittleness indexes, respectively, dimensionless; $K_{\mathrm{IC} \_ \text {max }}$ and $K_{\mathrm{IC} \_ \text {min }}$ are the maximum and the minimum fracture toughness, respectively, $\mathrm{MPa} \cdot \mathrm{m}^{1 / 2}$.

Based on these two methods, the fracability indexes of the studied sandstone samples were calculated, and the results are shown in Fig. 6.

As shown in Fig. 6, a higher brittleness index and a lower fracture toughness will lead to a higher fracability index, which is found to range from 0.05 to 0.40 using the product method and from 0.40 to 0.65 using the weighting method. The sensitivity of the fracability index is higher for the product method; thus, the fracability of the formation is easier to be distinguished. The most important difference between the product method and the weighting method is in regions where the brittle index and the fracture toughness are both lower or both higher: The fracability index of the product method in such regions is lower, and the fracability index of the weighting method in such regions is higher. The reason is that the weighting method in these regions is actually a single fracability evaluation based on brittleness index or fracture toughness. This analysis indicates that the product method is more reasonable to evaluate the fracability in this case.

It should be noted that the advantage of the weighting method is that different weighting coefficients can be selected for different types of lithology, and the weighting coefficient can reflect the influence of brittleness index or fracture toughness on the rock fracability. However, the specific values of weighting coefficients for different rocks need to be determined. Noted that the above method for fracability evaluation is developed for tight sandstones in the Junggar Basin. Similar study approaches may be applicable to other basins.

\section{Case analysis}

\subsection{Optimization of hydraulic fracturing sections}

Before evaluating the reservoir fracability, producing formations need to be determined based on logging data, fluorescence analysis, nuclear magnetic resonance, and other methods. The main characteristics of producing formations include high porosity, high permeability, high pore connectivity, and abundance of oil and gas. Taking Well B in the central Junggar Basin as an example, three segments of producing formations were identified ranging from 4436 to 4441,4466 to 4480 , and 4535 to $4539 \mathrm{~m}$.

The profile of brittleness index with depth was calculated by combining the newly developed equations of dynamic and static mechanical parameters of rocks and the logging data obtained in the field. The tensile strength of the rock was calculated by natural gamma logging data, lithology density logging data, and the dynamic modulus of elasticity. The profile of fracture toughness with depth was then determined from the tensile strength. Finally, the profile of fracability index was calculated using the product method. The calculation results are shown in Fig. 7.

From a comparative analysis of the brittleness index, fracture toughness, fracability index, and the location of producing formations in Fig. 7, the following findings are drawn:

1. Regions with high fracability indexes are highly correlated with producing formations. A critical fracability index is defined in a way that when the fracability index is higher than the critical value, the formation layer is a preferred layer for fracturing. A critical fracability index of 0.33 was selected for this well, and thus, the optimum sections for hydraulic fracturing were determined to be 4436 to $4441 \mathrm{~m}, 4470$ to $4480 \mathrm{~m}$, and 4535 to $4539 \mathrm{~m}$. It should be noted that in this case the sections with 


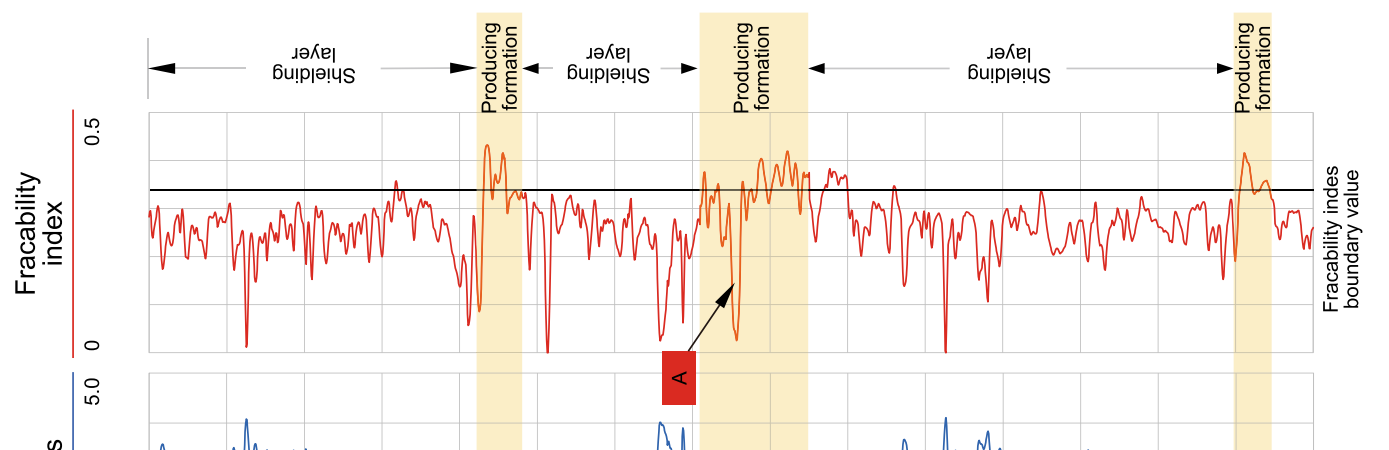

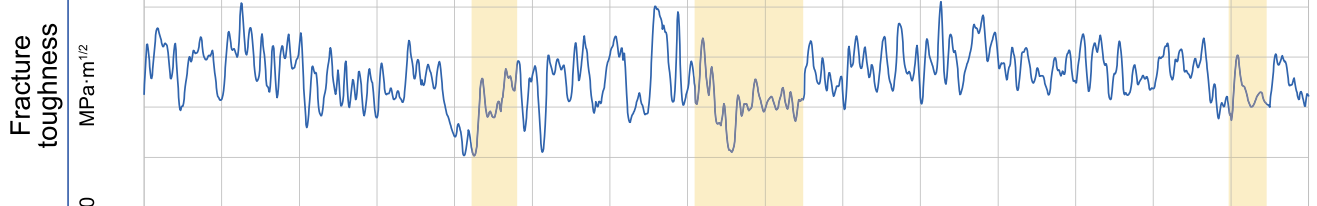

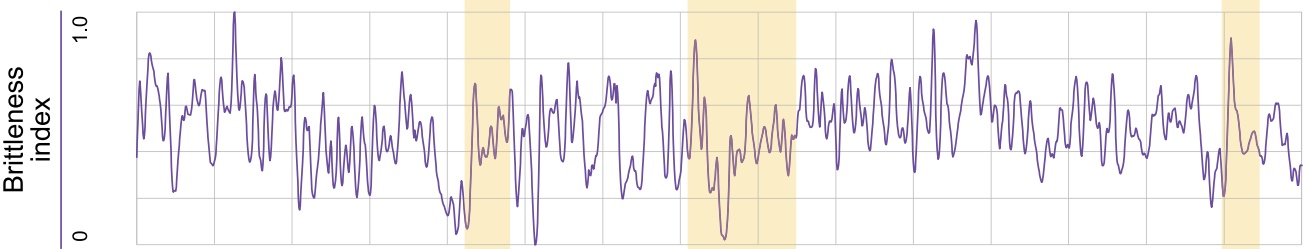

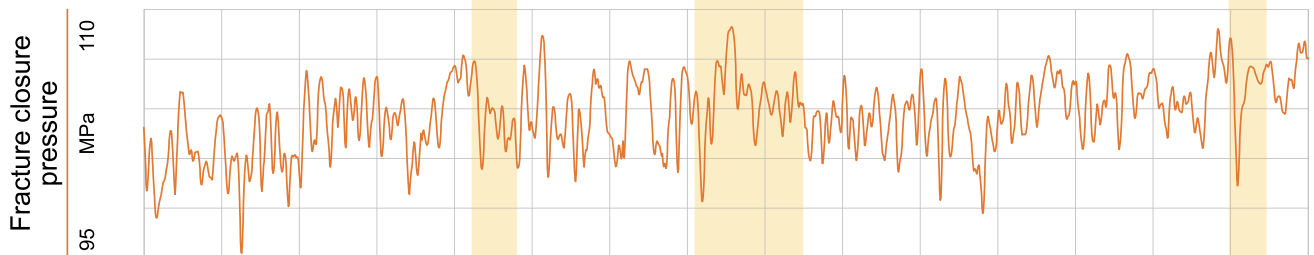

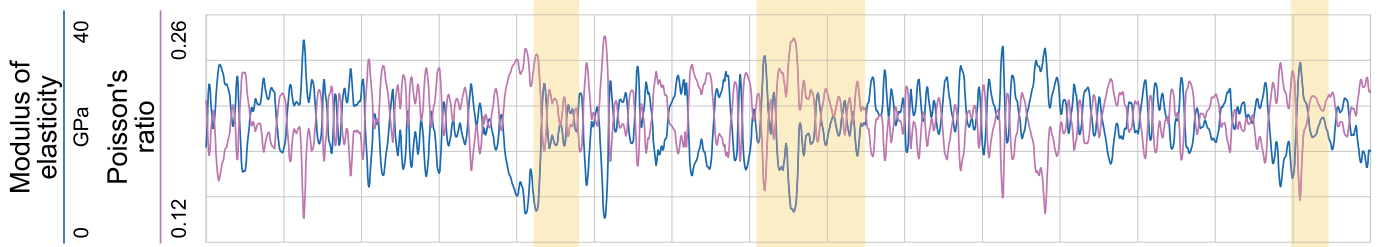

III In

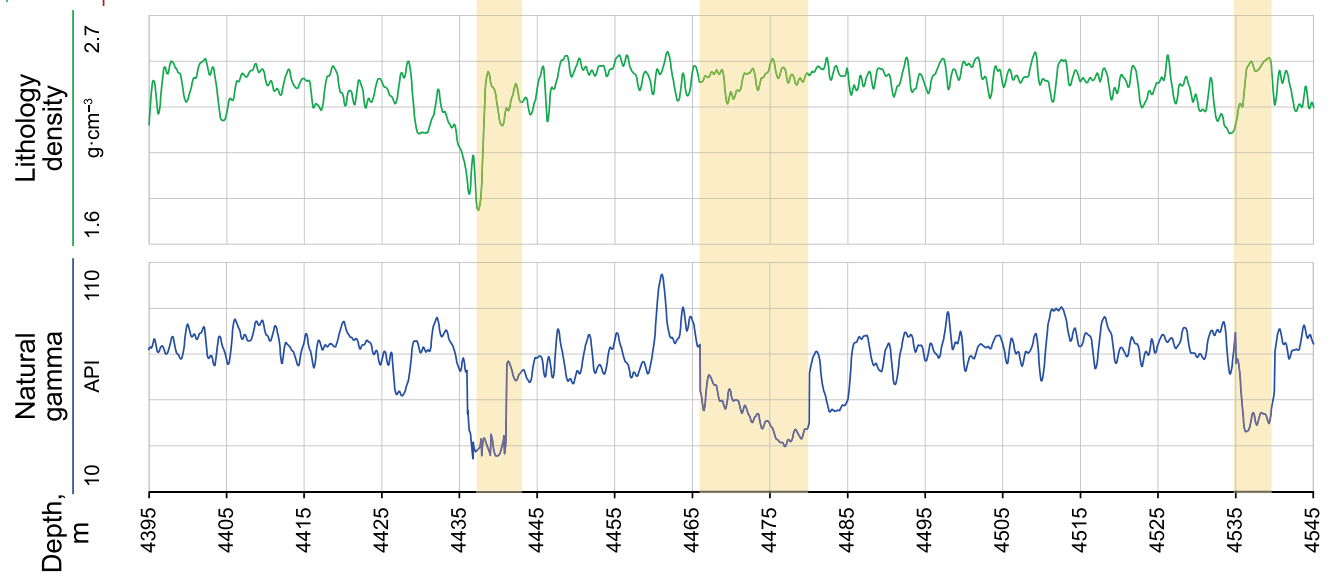

Fig. 7 Fracability evaluation map of the studied area 
high fracability are correlated with producing formations. However, generally, the productivity of a well is also influenced by many other factors, such as the oilbearing conditions, pressure, and physical properties of the formation.

2. The sections with high brittle indexes, such as 4395$4415 \mathrm{~m}$ and $4485-4505 \mathrm{~m}$, have low fracability indexes. This is because the fracture toughness of these sections is high, and thus, fractures easily propagate in these sections. The sections with low brittle indexes, such as 4430-4435 $\mathrm{m}$ and 4445-4465 m, also have low fracability indexes. This is because low brittle index results in greater difficulty for fracture initiation. It is concluded that the fracability index does not change monotonously with the brittleness index or fracture toughness. Thus, the optimum sections of hydraulic fracturing cannot be determined using the brittleness index or fracture toughness alone.

3. The section $4466-4480 \mathrm{~m}$ was determined to be the producing formation by considering various geological information. It is important to note that, according to fracability index, there is a shielding section about $2 \mathrm{~m}$ from 4469 to $4471 \mathrm{~m}$, as shown in Point A of Fig. 7. The wave slowness of this layer is long and the brittleness index is low, suggesting that this layer may be a mudstone, which will impede the transfer of fluid pressure and then reduce the effectiveness of fracturing. To break through the shading of the mudstone interlayer, greater pump displacement is often required. However, fracturing and denudation of mudstones with an excessive displacement is prone to cause migration of clay minerals along fractures, resulting in pollution and a poor fracturing effect. Further study of the fracture pressure and displacement is needed to optimize the hydraulic fracturing design to mitigate the influence of the mudstone interlayer.

\subsection{Field fracturing effectiveness}

The hydraulic fracturing scheme was designed according to the above selected optimum section of 4466 to $4480 \mathrm{~m}$. The fracturing fluid in the tight reservoir is difficult to flow back due to the low permeability of the reservoir after fracturing job. Thus, a $0.3 \%$ microemulsion was used to reduce water blocking, enhance flowback, and reduce formation damage. Closure pressure is high, and thus, high-strength ceramics were used as a support agent to improve the conductivity of fractures. To break through the mudstone interlayer inside the reservoir and, meanwhile, to avoid fracturing the adjacent shielding layer, an optimized sand amount of $30 \mathrm{~m}^{3}$ was used. Oil production of the optimum fracturing section in $48 \mathrm{~h}$ after the fracturing job is shown in Fig. 8 .

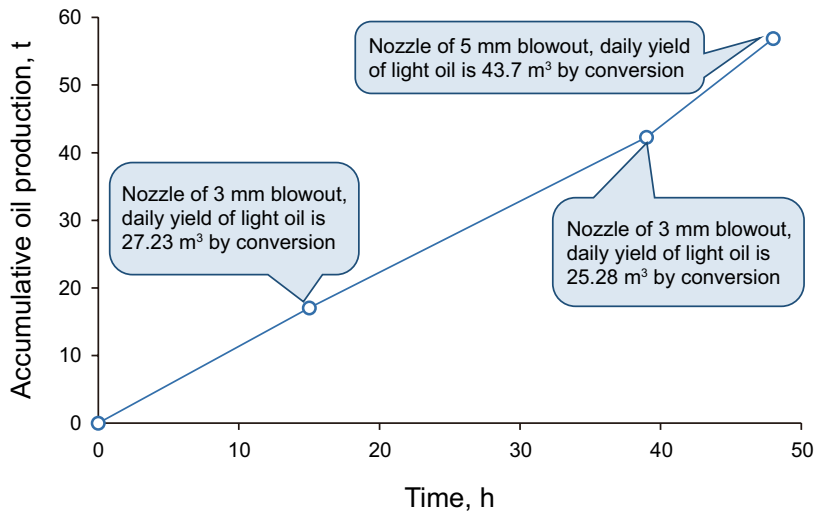

Fig. 8 Oil production in $48 \mathrm{~h}$ after hydraulic fracturing

Many factors can affect the productivity of a well, including fracturing stimulation, oil-bearing conditions, original pressure, and reservoir properties. However, within a short period after production ( $48 \mathrm{~h}$ in this case study), fracturing stimulation has a significant influence on oil production. As shown in Fig. 8, the average daily yield of oil is about $32.07 \mathrm{~m}^{3}$ after hydraulic fracturing, meeting the minimum requirements of production. It implies that the presented method for fracability index calculation and fracturing section selection is suitable for the development of tight oil reservoirs in the Junggar Basin.

\section{Conclusions}

In this study, triaxial tests were carried out to measure dynamic and static mechanical parameters of tight sandstone samples synchronously. Relationships between dynamic and static mechanical parameters of the rock and compressional and shear wave slowness of tight sandstones were established. A comparison between the weighting method and the product method demonstrates that the latter is a preferred method for fracability evaluation.

The proposed fracability evaluation method was applied to the tight oil reservoir in the central Junggar Basin, China. It is found that the producing formations and the regions with higher fracability index have a higher degree of correlation. A critical fracability index value of 0.33 was selected and three candidate sections for hydraulic fracturing were identified based on the critical fracability index. A mudstone interlayer in the producing formation was also identified. The reliability of the proposed fracability evaluation method was proven by the oil test results after hydraulic fracturing. Meanwhile, it implies that the established new relationships between dynamic and static mechanical parameters of the rock are applicable for tight reservoirs in the central Junggar Basin. 
Acknowledgements This work is supported by the National Science and Technology Major Project of the Ministry of Science and Technology of China (2016ZX05002-002) and the National Natural Science Foundation of China (41972138).

Open Access This article is distributed under the terms of the Creative Commons Attribution 4.0 International License (http://creativeco mmons.org/licenses/by/4.0/), which permits unrestricted use, distribution, and reproduction in any medium, provided you give appropriate credit to the original author(s) and the source, provide a link to the Creative Commons license, and indicate if changes were made.

\section{References}

Chen JG, Deng J, Yuan JL, et al. Determination of fracture toughness of Mode I and Mode II of shale formation. Chin J Rock Mech Eng. 2015;34(6):1101-5. https://doi.org/10.13722/j.cnki. jrme.2014.1187 (in Chinese with English abstract).

Chen ZX, Chen M, Yan J. Experimental study on the relationship between rock fracture toughness and acoustic velocity. Oil Drill Prod Technol. 1997;19(5):56-60. https://doi.org/10.13639 /j.odpt.1997.05.017 (in Chinese with English abstract).

Govindarajan S, Gokaraju DV, Mitra A, et al. Evaluation of fracability index for reservoir rock-a laboratory study. In: 51st US rock mechanics/geomechanics symposium. American Rock Mechanics Association; 2017. https://www.onepetro.org/conference-paper/ ARMA-2017-0381

Irwin GR. Analysis of stresses and strains near the end of a crack traversing a plate. J Appl Mech. 1956;24:361-4.

Jin X, Shah SN, Roegiers JC, et al. Fracability evaluation in shale reservoirs - an integrated petrophysics and geomechanics approach. SPE J. 2014;20:518-26. https://doi.org/10.2118/168589-MS.

Jin Y, Chen M, Zhang XD. Determination of fracture toughness for deep well rock with geophysical logging data. Chin J Rock Mech Eng. 2001;20:454-6. https://doi.org/10.3321/j.issn:10006915.2001.04.007 (in Chinese with English abstract).

Li J, Zha M, Liu Z. Research on crustal stress distribution based on acoustic logging data-Taking North Region of Renqiu
Ordovician Buried Hill of Raoyang Depression for example. Rock Soil Mech. 2011;32:2765-70. https://doi.org/10.16285 /j.rsm.2011.09.031 (in Chinese with English abstract).

Li JB, Lu SF, Chen GH, et al. Friability evaluation for the mud shale reservoirs based on the mineralogy and rock mechanics. Pet Geol Oil Dev Daq. 2015;34:159-64. https://doi.org/10.3969/J. ISSN.1000-3754.2015.06.029 (in Chinese with English abstract).

Li QH, Chen M, Jin Y, et al. Indoor evaluation method for shale brittleness and improvement. Chin J Rock Mech Eng. 2012;31:1680-5. https://doi.org/10.3969/j.issn.1000-6915.2012.08.023 (in Chinese with English abstract).

Rickman R, Mullen MJ, Petre JE, et al. A practical use of shale petrophysics for stimulation design optimization: all shale plays are not clones of the Barnett Shale. In: SPE annual technical conference and exhibition, 21-24 September, Denver, Colorado, USA; 2008. https://doi.org/10.2118/115258-MS.

Sierra R, Tran MH, Abousleiman YN, et al. Woodford shale mechanical properties and the impacts of lithofacies. In: US rock mechanics symposium \& US-Canada rock mechanics symposium. Salt Lake City, USA: American Rock Mechanics Association; 2010. p. 2033-5. https://www.onepetro.org/conference-paper/ ARMA-10-461.

Sun JM, Han ZL, Qin RB, et al. Log evaluation method of fracturing performance in tight gas reservoir. Acta Pet Sin. 2015;36:74-80. https://doi.org/10.7623/syxb201501009 (in Chinese with English abstract).

Tarasov B, Potvin Y. Universal criteria for rock brittleness estimation under triaxial compression. Int J Rock Mech Min. 2013;59:57-69. https://doi.org/10.1016/j.ijrmms.2012.12.011.

Winkler K, Nur A, Gladwin M. Friction and seismic attenuation in rocks. Nature. 1979;277(5697):528-31. https://doi. org/10.1038/277528a0.

Yuan J, Zhou J, Liu S, et al. An improved fracability-evaluation method for shale reservoirs based on new fracture toughnessprediction models. SPE J. 2017;22(05):1704-13. https://doi. org/10.2118/185963-PA. 